\title{
CAN COST OF PHARMACOLOGICAL THROMBOLYTIC THERAPY BE A MEDICATION MANAGEMENT STRATEGY FOR ACUTE CORONARY SYNDROME?
}

\author{
VINOD KUMAR, BIJOY KUMAR PANDA* \\ Department of Clinical Pharmacy, Poona College of Pharmacy, Bharati Vidyapeeth University, Pune, Maharashtra, India. \\ Email: bijoymaximus@gmail.com
}

Received: 23 November 2016, Revised and Accepted: 20 December 2016

\begin{abstract}
Objectives: In Indian health-care system with delayed access to a minimum number of catheter laboratories and rarity of insurance benefits, prehospital and in-hospital thrombolytic has become the choice for patients with acute coronary syndrome (ACS), where many patients bear the economic burden of pharmacological thrombolytic. The present study was carried out to evaluate the pattern of prescribing of pharmacological thrombolytic agents in hospitalized ACS patients and associated cost burden.
\end{abstract}

Methods: A prospective observational cohort study of prescription was conducted for in-patient admitted to intensive care unit for thrombolytic and antithrombotic drug utilization pattern. The direct cost analysis was performed from patient's perspective where a direct cost was calculated using pharmacy bills. All other cost was assumed to be same.

Results: Data of 288 patients were collected from which 108 (37.5\%) patients were ST-elevation myocardial infarction (STEMI) and 180 (62.5\%) patients were non-STEMI. The mean number of drugs prescribed was $11 \pm 2$ which constitutes a mean of $3.1 \pm 0.7$ reperfusion drugs. $59 \%$ of patients were prescribed with enoxaparin $(0.6 \mathrm{ml} / \mathrm{seconds}$ route) for the mean duration of 4 days. The average prescription cost for ACS admission was around Rs.7159.5 \pm 5137.2 (Rs.1101-Rs.22202). The average cost of pharmacological thrombolytic therapy was Rs.4557 \pm 3468.3 (Rs. 23-Rs.12542). The mean cost of pharmacological thrombolytic therapy was found to be $63 \%$ of the total direct cost of drugs borne by the patient. The cost of therapy was positively correlated with duration of stay $(\mathrm{p}=0.000)$ and insignificantly correlated with a number of drugs.

Conclusion: Antiplatelets were the most preferred followed by anticoagulants. The mean number of drugs per encounter was high but was rational as per standard guidelines. The mean cost for pharmacological reperfusion therapy was found to be more than half of mean prescription cost for the management of ACS.

Keywords: Acute coronary syndrome, Thrombolytic therapy, Cost, Medication management.

(C) 2017 The Authors. Published by Innovare Academic Sciences Pvt Ltd. This is an open access article under the CC BY license (http://creativecommons. org/licenses/by/4. 0/) DOI: http://dx.doi.org/10.22159/ajpcr.2017.v10i3.16308

\section{INTRODUCTION}

Cardiovascular diseases (CVDs)-related deaths in 2002 were more in India compared to other countries of the world. 52\% of CVD in India occur below the age of 50 years and about $25 \%$ of acute myocardial infarction (AMI) in India occur below the age of 40 years. Disabilityadjusted life years lost due to CAD per 1000 populations in India are three times higher than in developed countries, thus having sustainable implication on Indian growing workforce [1-4]. Rates of primary percutaneous coronary intervention (PCI) were lower while that of thrombolytic treatment was higher than in developed countries. This is probably because three-fourth of the patients in India have to pay directly for their own treatment. The rates of coronary artery bypass graft were even lower in Indian patients. The reasons for poor invasive cardiac procedures are numerous and evident [1]. In Indian condition with delayed access to a minimum number of catheter laboratories and insurance benefits being a rarity, pre-hospital and in-hospital fibrinolytics have become the choice for patients with acute coronary syndrome (ACS) presenting early; however, adjunct antithrombotic agents and antiplatelet drugs maximize and maintain the drug dissolving effects and PCI [1].

The absolute pharmacoinvasive goal of ST-elevation myocardial infarction (STEMI) is to achieve earliest possible reperfusion. Several agents such as fibrinolytic, thrombolytic, and antiplatelet agents are proved to be beneficial in acute treatment phase. Various combinations of fibrinolytics and antithrombotics are practiced for the management of STEMI and non-NSTEMI. There are many literatures on cost-effective comparisons done between various reperfusion agents performed in developed countries [5]. There is hardly any outcome analysis done to assess the cost burden of reperfusion, antithrombotic, and antiplatelet drugs strategies for management of ACS in developing countries.

Our study focuses on the pattern of thrombolytic and antithrombotic therapy initiated in STEMI and NSTEMI and cost implications due to various thrombolytic strategies. This will help us to suggest intervention strategies to reduce the cost burden on patients.

\section{METHODS}

A prospective observational cohort study was carried out in intensive care unit (ICU) of a tertiary teaching hospital after obtaining approval from the Institutional Ethics Committee. Study was carried out over a period of 9 months from September 2014 to August 2015. In-patients with complaints of chest pain, breathlessness, palpitation, and sweating (either anyone with chest pain) were enrolled in the study. Patient population included both STEMI and NSTEMI which was confirmed after doing electrocardiogram.

Demographic data were recorded on the case record form. Patients' clinical data including diagnosis, detailed history of illness, past history, and family history were noted. Information on drugs prescribed and administered was obtained from the patient's chart. The date started and discontinued, the route of administration, and the quantity were 
entered for each distinct drug. Cost analysis was performed from patient's perspective. The cost of the drug was defined as the acquisition cost to the patient by the retail pharmacy within the hospital campus. Direct cost of pharmacological treatment was calculated using patient's pharmacy bills. In each case, the price was calculated finally on a per unit basis for the strength and form actually used and then multiplied by a number of units actually administered to determine the cost of each drug received by a patient. Cost figures were assembled for each drug received by a patient, for all drugs received during an admission, and for all drugs prescribed in hospitals. Finally, total cost for all drugs received by the patients during 12 months period was calculated.

\section{Statistical analysis used}

The standard descriptive statistics were used, and all the collected data were analyzed using Microsoft Excel spreadsheet and interpreted. The results were evaluated against the set criteria and thresholds and presented in tables and figures. The data were represented as mean, numbers, or percentages. Pearson's coefficient used to correlate between a number of drugs, stay in days, and cost of therapy. $\mathrm{p}<0.05$ was considered statistically significant.

\section{RESULTS}

A total of 288 patients were included with the first diagnosis of AMI over duration of 12 months from which $108(37.5 \%)$ patients were STEMI and $180(62.5 \%)$ patients were NSTEMI. Mean age of patients was $59 \pm 9$ years. Most of the patients were male, i.e., $189(65.62 \%)$. Majority of the patients belong to the age group of 40-60 years $(n=144)$ which comprised about $50 \%$ of total patients (Table 1). Hypertension and type II diabetes mellitus constituted majorly as comorbid conditions in the age group of 61-80 years ( $\mathrm{n}=81$ ) (Fig. 1). Most of the patients presented with chest pain $(n=279)$ and breathlessness $(n=117)$. Mean stay in ICU was $6 \pm 4$ days.

A total of 3201 drugs were prescribed in 288 patients. Mean number of drugs prescribed per patients was 11. Antiplatelet drugs were most frequently prescribed drugs in $92.5 \%$ of the patients. Aspirin $270(93.75 \%)$ was most frequently prescribed drug followed by clopidogrel 261 (90.62\%). Low molecular weight heparin (LMWH) preferably, enoxaparin and unfractionated heparin (UFH) were equally

Table 1: Demographic details of AMI in-patients

\begin{tabular}{|c|c|}
\hline \multicolumn{2}{|c|}{ Age/sex distribution of patient with AMI } \\
\hline Age group & Total number of patient (\%) \\
\hline $40-60$ & $144(50)$ \\
\hline $61-80$ & $135(46.8)$ \\
\hline$>80$ & $9(3.12)$ \\
\hline \multicolumn{2}{|c|}{ Length of stay during first admission } \\
\hline Length of stay & Number of patients (\%) \\
\hline $1-3$ & $36(12.5)$ \\
\hline $4-7$ & $216(75)$ \\
\hline 8-13 & $18(6.25)$ \\
\hline $14-20$ & $18(6.25)$ \\
\hline \multicolumn{2}{|c|}{ Number of drugs administered to patient during first admission } \\
\hline Number of drugs & Number of patients (\%) \\
\hline 1 & $9(3.12)$ \\
\hline 2 & $45(15.62)$ \\
\hline 3 & $153(53.12)$ \\
\hline 4 & $81(28.12)$ \\
\hline \multicolumn{2}{|l|}{ Route of administration } \\
\hline Route of administration & Number of drugs (\%) \\
\hline By mouth & $540(61.22)$ \\
\hline Intravenous & $162(18.36)$ \\
\hline Subcutaneous & $180(20.40)$ \\
\hline
\end{tabular}

AMI: Acute myocardial infarction practiced as anticoagulants either alone or together (administered on a different day) in each of the 171 (59\%) patients. Streptokinase was used as initial fibrinolytic agent only limited to 108 (37.5\%) patients (Table 2).

The other class of drugs prescribed was antihyperlipidemia (atorvastatin) and antiemetic (ondansetron) in $90.62 \%$. Pantoprazole was prescribed in $87 \%$ patients. A total of $180(62.5 \%)$ antimicrobial drugs were used among which commonly prescribed was ceftriaxone $(31.25 \%)$.

Mean total cost of pharmacotherapy per patient was Rs. $7159.5 \pm 5137.2$ among which the mean cost for thrombolytic and antithrombotic therapy was Rs. $4557 \pm 3468.3$ (Fig. 2). Average number of drugs per patient was found to be $11 \pm 2$. Duration of ICU stay was not positively correlated with number of drugs (Pearson's correlation $r=0.31$, $\mathrm{p}=0.08$ ). Cost of therapy was positively correlated with duration of stay (Pearson's correlation $r=0.59, p=0.000$ ) and not positively correlated with number of drugs (Pearson's correlation $r=0.27, p=0.12$ ).

\section{DISCUSSION}

The study was carried out with the aim to estimate the cost incurred for pharmacological thrombolytic and antithrombotic therapy during a hospital stay in ACS patients and to identify the indicators that decline the cost of the same. The mean age of patients in our study was slightly lower when compared to a study that reported $60.45 \pm 12.45$ and 64 years [6]. The majority of the patients in our study were male which is comparable to earlier Indian and foreign studies [7,8]. In our study, prevalence of hypertension and type 2 diabetes is generally $50 \%$. However, in our study, the prevalence of these comorbid conditions was lower than in Indian study performed [9]. A pattern of comorbid condition varies within study population. Mean stay in ICU was higher

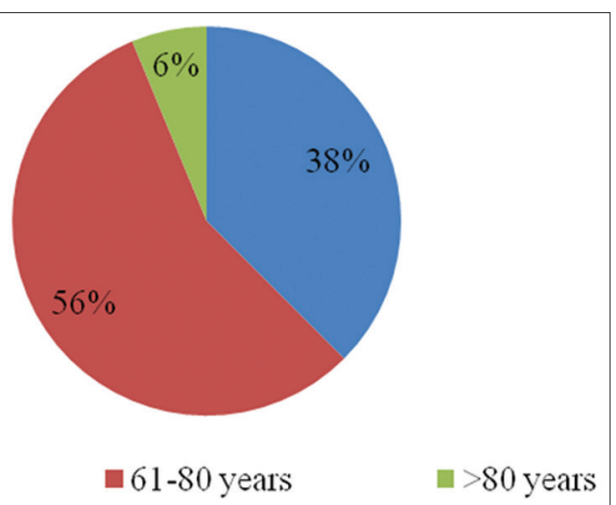

40-60 years

$61-80$ years

$>80$ year:

Fig. 1: Percentage distribution of co-morbidities in various age groups

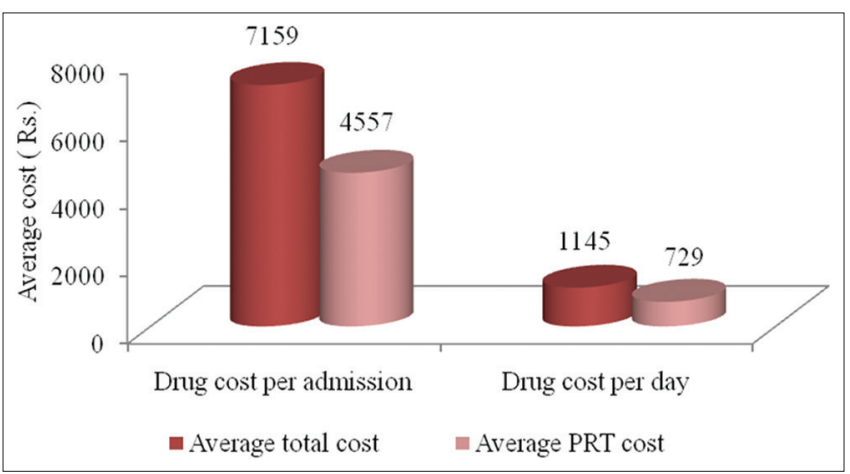

Fig. 2: Average cost of pharmacological reperfusion and thrombolytic from total cost 
Table 2: Percentage prescribing and cost (Rs.) accrued for individual pharmacological thrombolytic therapy

\begin{tabular}{lllll}
\hline Drug group & Drugs & ATC code & $\begin{array}{l}\text { Number of } \\
\text { patient, n (\%) }\end{array}$ & $\begin{array}{l}\text { Total } \\
\text { cost (Rs.) }\end{array}$ \\
\hline Antiplatelet & Aspirin & B01AC06 & $90(93.75)$ & 179.1 \\
& Clopidogrel & B01AC04 & $87(90.62)$ & 2772 \\
Anticoagulant & Enoxaparin & B01AB05 & $57(59.37)$ & 329920.8 \\
& UFH & B01AB03 & $57(59.37)$ & 21840 \\
& Warfarin & B01AD04 & $3(3.12)$ & 90 \\
Fibrinolytic & Streptokinase & B01AD01 & $36(37.5)$ & 82285.5 \\
\hline
\end{tabular}

UFH: Unfractionated heparin

compared with other studies $[10,11]$. The possible reasons may be due to difference in practice policies in different hospitals. Duration of ICU stay was not positively correlated with a number of drugs which contradicts the known fact [12], possibly due to the management strategy followed in ACS.

In an Indian study [13], mean number of drugs was more than 10, which was also observed in our study but was in contrast to a study that reported prescribing of $<10$ drugs per patient [6]. This difference can be due to difference in morbidity pattern and different prescribing practices in different countries. As per ACC/AHA guidelines, there are three classes of recommendations. Class 1 drugs are those having highest benefit-risk ratio and recommended. Class 2 drugs are those with somewhat less benefit-risk ratio compared with class 1 and are probably recommended. Class 3 drugs are those that are not recommended or potentially harmful. In our study considering rationality based on ACC/AHA guidelines for ACS in all NSTEMI patients, guidelines were adhered to. As far as drug therapy for STEMI is concerned, majority of prescriptions adhered to the guidelines in the form of Classes 1 and 2 recommendations. The use of aspirin, clopidogrel, UFH, LMWH, and fibrinolytics was used as clot dissolving and prevention cocktail strategies according to standard ACC/AHA guidelines [14].

Antiplatelet drugs were most frequently prescribed, it was found to similar and comparable to other studies [15]. Aspirin and clopidogrel were mostly preferred for inhibition of blood clots in coronary artery and peripheral vessels in majority of the patients. In our study, none of the patients received GP III/IIa receptor antagonist as none of our patients underwent primary PCI. Only one-third of the patients received fibrinolytics depending on their early presentation, and more than $50 \%$ were prescribed with enoxaparin and UFH. Streptokinase was not commonly used agent compared to LMWH and UFH though it is the least expensive option available. This is due to questionable effect on late presentation to hospital and possible adverse effects [16]. Other studies had a higher use of thrombolytics as compared to our study in suspected ACS [17-19]. UFH alone has been used for anticoagulation in the majority of patients after undergoing fibrinolysis (streptokinase). Even LMWH has been preferred alone as well as after fibrinolysis in STEMI patients. More than one-third of the patients were prescribed initially with UFH and then switched to LMWH after 1-2 days. This strategy is probably used because of half-life of UFH is 30-60 minutes as compared to enoxaparin having half-life of 4-6 hrs [20]. Switching strategy is preferred as many evidence suggest LMWH as an effective alternative antithrombotic therapy to UFH because of its favorable pharmacokinetic profile and clinical advantages [15,21,22]. In our study, LMWH has been used in more than $60 \%$ of patients because of its safety profile compared to UFH. Warfarin is least preferred among all the anticoagulant because of its side effects' profile and frequent monitoring.

Mean cost of pharmacotherapy was higher compared to other few Indian studies [8]. Among all drugs, $41.1 \%$ were administered parenterally adding a significant cost burden to patients. About $83 \%$ of total cost of pharmacological therapy was attributed to these parenteral drugs. It was found that about $64 \%$ of cost was attributed to reperfusion therapy from the total cost. LMWH alone accrued $48 \%$ of cost burden on patients from cost of reperfusion therapy. This is due to high cost of LMWH available in the market ranging from Rs. 409 to 579 . Enoxaparin (Rs. 579) has been the preferred LMWH in mean dose $0.6 \mathrm{ml}$ administered subcutaneously for a mean duration of 4 days. Fondaparinux is the least preferred in our study though one of the studies reported it to be cost saving alternative among the available LMWH [23].

\section{Recommendations}

1. Including a cost-effective alternative of enoxaparin brand available in the market can reduce the price burden from $48 \%$ to $32 \%$. This can be properly implemented if there would have been a formulary guided by pharmacist and proper drug utilization studies.

2. Another strategy to overcome the price burden would be to continue with streptokinase followed by UFH (least cost) for the in-patients associated with least risk factors and no observed contraindications as they are under continuous monitoring in the ICU.

These recommendations may require a formulary-based intervention study to measure the cost burden on the patient for the management of ACS.

\section{CONCLUSION}

Antiplatelets were the most preferred followed by anticoagulants. Mean number of drugs per encounter was high but was rational as per standard guidelines. The mean cost for pharmacological reperfusion therapy was found to be more than half of mean prescription cost for management of ACS. LMWH (Enoxaparin) was found to accommodate the maximum cost of treatment per patient. Incorporating a cheaper cost-effective LMWH can save one-third of pharmacological cost and one-fourth of total prescription. Streptokinase and UFH can be preferred strategy to reduce the substantial cost burden of reperfusion therapy, until unless contraindicated.

\section{REFERENCES}

1. Liu Y, Dalal K. Review of cost-effectiveness analysis of medical treatment for myocardial infarction. Int J Prev Med 2011;2(2):64-72.

2. Gonzalez ER. Acute myocardial infarction. Textbook of Therapeutics: Drug and Disease Management. $8^{\text {th }}$ ed. Philadelphia, PA: Lippincott Williams \& Wilkins; 2006. p. 397.

3. Dalal J, Sahoo PK, Singh RK, Dhall A, Kapoor R, Krishnamurthy A, et al. Role of thrombolysis in reperfusion therapy for management of AMI: Indian scenario. Indian Heart J 2013;65(5):566-85.

4. Mardikar HM, Deshpande NV, Admane P. Recent advances in the management of acute myocardial infarction. J Assoc Physicians India 2011;59 Suppl:31-6.

5. Barron HV, Bowlby LJ, Breen T, Rogers WJ, Canto JG, Zhang Y, et al. Use of reperfusion therapy for acute myocardial infarction in the United States: Data from the National Registry of Myocardial Infarction 2. Circulation 1998;97(12):1150-6.

6. Al-Junid SM, Ezat WP, Surianti S. Prescribing pattern and drug cost among cardiovascular patients in Hospital University Kebangsaan Malaysia. Med J Malaysia 2007;62(1):59-65.

7. Anand SS, Islam S, Rosengren A, Franzosi MG, Steyn K, Yusufali AH, et al. Risk factors for myocardial infarction in women and men: Insights from the INTERHEART study. Eur Heart J 2008;29(7):932-40.

8. Kannel WB, Hjortland MC, McNamara PM, Gordon T. Menopause and risk of cardiovascular disease: The Framingham study. Ann Intern Med 1976;85(4):447-52.

9. Wal P, Wal A, Nair VR, Rai AK, Pandey U. Management of coronary artery disease in a tertiary care hospital. J Basic Clin Pharm 2013;4(2):31-5.

10. Saczynski JS, Lessard D, Spencer FA, Gurwitz JH, Gore JM, Yarzebski J, et al. Declining length of stay for patients hospitalized with AMI: Impact on mortality and readmissions. Am J Med 2010;123(11):1007-15.

11. Li Q, Lin Z, Masoudi FA, Li J, Li X, Hernández-Díaz S, et al. National trends in hospital length of stay for acute myocardial infarction in China. BMC Cardiovasc Disord 2015;15:9.

12. Shankar R, Partha P, Shenoy N. Prescribing patterns of drugs among 
patients admitted with cardiovascular disorders in the internal medicine ward: Prescribing patterns in inpatients. Int J Pharmacol 2001;1(2):1-5.

13. Patel VK, Acharya LD, Rajakannan T, Surulivelrajan M, Guddattu V, Padmakumar R. Potential drug interactions in patients admitted to cardiology wards of a South Indian teaching hospital. Australas Med J 2011;4(1):9-14.

14. Amsterdam EA, Wenger NK, Brindis RG, Casey DE Jr, Ganiats TG, Holmes DR Jr, et al. 2014 AHA/ACC guideline for the management of patients with non-ST-elevation acute coronary syndromes: Executive summary: A report of the American College of Cardiology/American Heart Association Task Force on Practice Guidelines. Circulation 2014;130(25):2354-94

15. Christian RP, Rana DA, Malhotra SD, Patel VJ. Evaluation of rationality in prescribing, adherence to treatment guidelines, and direct cost of treatment in intensive cardiac care unit: A prospective observational study. Indian J Crit Care Med 2014;18(5):278-84.

16. Kumolosasi E, Wei WS, Wee CE. The use of thrombolytic agents in acute myocardial infarction (AMI) patients. Int J Pharm Pharm Sci 2013;7(3):183-5.

17. Frostfeldt G, Ahlberg G, Gustafsson G, Helmius G, Lindahl B, Nygren A, et al. Low molecular weight heparin (dalteparin) as adjuvant treatment of thrombolysis in acute myocardial infarction - a pilot study: Biochemical markers in acute coronary syndromes (BIOMACS II). J Am Coll Cardiol 1999;33(3):627-33.
18. Rubboli A. Efficacy and safety of low molecular weight heparin as adjuvant to thrombolysis in acute ST - Elevation myocardial infarction. Curr Cardiol Rev 2008;4(1):63-71.

19. Eikelboom JW, Quinlan DJ, Mehta SR, Turpie AG, Menown IB, Yusuf S. Unfractionated and low molecular weight heparin as adjuncts to thrombolysis in aspirin - Treated patients with ST - Elevation acute myocardial infarction. Am Heart Assoc 2005;112(25):3855-67.

20. Alldredge BK, Corelli RL, Ernst ME, Guglielmo BJ, Jacobson PA, Kradjan WA, et al. Applied Therapeutics: The Clinical Use of Drugs. $9^{\text {th }}$ ed. Philadelphia, PA: Lippincott Williams and Wilkins; 2009. p. 348.

21. Antman EM, Morrow DA, McCabe CH, Murphy SA, Ruda M, Sadowski Z, et al. Enoxaparin versus unfractionated heparin with fibrinolysis for ST-elevation myocardial infarction. N Engl J Med 2006;354(14):1477-88

22. Marcoff L, Zhang Z, Zhang W, Ewen E, Jurkovitz C, Leguet P, et al. Cost effectiveness of enoxaparin in acute ST-segment elevation myocardial infarction: The ExTRACT-TIMI 25 (Enoxaparin and Thrombolysis Reperfusion for Acute Myocardial Infarction TreatmentThrombolysis in Myocardial Infarction 25) study. J Am Coll Cardiol 2009;54(14):1271-9.

23. Alam S, Naqvi SB, Ahmed M. Drug utilization and economic impact of anticoagulants in unstable angina/non - ST elevation myocardial infarction in Karachi. Int J Pharm Pharm Sci 2015;7(3):183-5. 